Arq. Bras. Med. Vet. Zootec., v.71, n.1, p.331-339, 2019

\title{
Montagem de cariótipos de peixes assistida por computador
}

\author{
[Computer assisted fish karyotyping] \\ J.C. Klock ${ }^{1}$, C.R.M. Mauricio $^{2}$, F.K. Schneider ${ }^{3}$, D.R. Blanco ${ }^{4}$ \\ ${ }^{1}$ Aluna de pós-graduação - Universidade Tecnológica Federal do Paraná- UTFPR - Curitiba, PR \\ ${ }^{2}$ Universidade Estadual do Oeste do Paraná -Unioeste- Foz do Iguaçu, PR \\ ${ }^{3}$ Universidade Tecnológica Federal do Paraná- UTFPR - Curitiba, PR \\ ${ }^{4}$ Universidade Tecnológica Federal do Paraná -UTFPR - Santa Helena, PR
}

\begin{abstract}
RESUMO
A obtenção de cariótipos de peixes desempenha um papel importante em estudos de citotaxonomia e evolução cromossômica das espécies. No entanto, poucos sistemas semi ou completamente automatizados para a obtenção de cariótipo de peixes estão disponíveis. Este trabalho propõe e avalia uma ferramenta baseada em imagens que auxilie a montagem de cariótipos de peixes. As espécies analisadas foram Hopliasmalabaricus (Bloch, 1794); Hypostomusancistroides (Ihering, 1911) e Parauchenipterusgaleatus (Linnaeus, 1766); popularmente conhecidas como traíra, cascudo e bagre-sapo, respectivamente.Um total de 100 metáfases foi analisado por dois métodos: 1 - geração semiautomática de cariótipo e 2 - geração automática de cariótipo. A avaliação do sistema foi feita por meio da correlação de Pearson, gráficos de diferenças e tabelas de contagens,utilizando-se como referência a média das contagens feitas por quatro usuários. No método 1, quatro usuários realizaram contagens e apresentaram correlação interobservador de $\mathrm{r} \geq 0.997$. O número total de cromossomos identificados pelo método 1 foi 4348 e, para o método 2 , foi 4135 ,o que resultou em uma identificação automática de aproximadamente $95,1 \%$ dos cromossomos, resultando em correlação entre os dois métodos de $r=0.93$. Conclui-se que a ferramenta pode ser inserida no procedimento de cariotipagem de peixes para acelerar o processo com níveis aceitáveis de exatidão.
\end{abstract}

Palavras-chave: cariotipagem de peixes assistida por computador, cariótipo, Hopliasmalabaricus, Hypostomusancistroides, Parauchenipterusgaleatus

\begin{abstract}
Fish karyotyping plays an important role in studies of cytotaxonomy and chromosomic evolution of species. However, few semi or completely automated fish karyotyping systems are available. This work proposes and evaluates an image-based tool to assist fish karyotyping. The analyzed species were Hopliasmalabaricus (Bloch, 1794), Hypostomusancistroides (Ihering, 1911), and Parauchenipterusgaleatus (Linnaeus, 1766). In Portuguese, these species are commonly referred to as traira, cascudo, and bagresapo, respectively. A total of 100 metaphases were analyzed through two methods: (1) semi-automatic karyotype generation and (2) automatic karyotype generation. The results were analyzed using Pearson correlation, difference graphs and counting tables. The reference used for the evaluation of the system was the average of the counts made by four experts. In method 1, four users performed counts with interobserver correlation of $r \geq 0.997$. The total number of chromosomes identified by method 1 was 4348 and method 2 was 4135, excluding false positives, resulting in an automatic identification of approximately 95,1\% of the chromosomes, resulting in a correlation between the methods of $r=0.93$. The results indicate that the tool can be introduced for fish karyotyping procedures contributing for accelerating the process with acceptable accuracy.
\end{abstract}

Keywords: computer assisted fish karyotyping, Hopliasmalabaricus, Hypostomusancistroides, karyotype, Parauchenipterusgaleatus

Recebido em 9 de agosto de 2017

Aceito em 11 de outubro de 2017

E-mail: joyceklock@gmail.com 


\section{INTRODUÇÃO}

Conhecer e estudar a evolução cromossômica e a de sequências espécie-específicas é de grande importância para a taxonomia de espécies. Nesse contexto, há uma ciência que, desde seu início, uniu conhecimentos da citologia e da genética, dando origem a uma área comum, chamada citogenética. Essa ciência atualmente compreende todo e qualquer estudo relativo ao cromossomo, bem como sua morfologia, organização, função e replicação, levando em consideração a sua variação e evolução(Guerra, 1988).Esse campo de estudo surgiu no início do século $\mathrm{XX}$, quando os cientistas perceberam que os cromossomos são os carreadores dos genes. A citogenética é o estudo dos cromossomos e do seu papel na hereditariedade (O'Connor, 2008).

No âmbito da ciência chamada genética, o termo cariótipo é a descrição das características do conjunto cromossômico de uma espécie(Guerra, 1988).O estudo do cariótipo de diversos organismos tem como objetivo observar variações numéricas e estruturais, a fim de elucidar a evolução cromossômica das espécies.

O processo de montagem de um cariótipo é conhecido como cariotipagem e é obtido por meio de uma fotomicrografia de uma célula em fase de divisão celular na fase de metáfase mitótica. A cariotipagem envolve o pareamento dos cromossomos homólogos e a ordenação decrescente dos cromossomos pareados separados por morfologia, provendo a visualização genômica dos cromossomos de um indivíduo. A maior aplicabilidade da citogenética de peixes se refere aos estudos de evolução cromossômica e citotaxonomia(Artoni et al., 2000).

Tais estudos se demonstram de grande importância, no entanto poucos sistemas semi ou completamente automatizados para a obtenção de cariótipo de peixes são encontrados na literatura. Em estudo na literatura, encontrou-se um sistema de montagem de cariótipo de peixe baseado em conjuntos difusos (Faria, 2006),bem como um sistema para análise e montagem de cariótipo de peixe, feito de maneira manual (Bressane-Neto et al., 2005). Trata-se de dois trabalhos voltados para a solução do problema em questão, não disponíveis, entretanto,para uso da comunidade científica.Devido a isso, há uma grande necessidade de se obter uma ferramenta semi ou completamente automatizada para esse fim.

A engenharia biomédica, que reúne princípios e conceitos das ciências exatas e das ciências biológicas, desenvolvendo abordagens inovadoras aplicadas à elaboração de sistemas de análise, será de grande importância na resolução desse problema.De posse desse entendimento e compreensão, este trabalho visa unir os conhecimentos da citogenética de peixes com os conhecimentos de ciência da computação, para o desenvolvimento de uma ferramenta baseada em imagens que auxiliem a montagem do cariótipo de peixe, por meio de uma fotomicrografia de células de peixe em divisão (metáfase), feita pelos citogeneticistas.

A palavra karyotype é derivada do grego karyon, que significa núcleo, e de typos, que significa imprimir. O cariótipo é a descrição das características do conjunto cromossômico de uma espécie (Guerra, 1988).

Para se obter a montagem do cariótipo de peixe, é necessário obter uma fotomicrografia de uma célula de peixe em metáfase mitótica. A imagem adquirida, geralmente, apresenta artefatos $\mathrm{e}$ baixo contraste.

Em seguida, é preciso recortar cada cromossomo da imagem para ser analisado individualmente. A posição do centrômero é determinada pelo citogeneticista.

Depois de marcar o centrômero de cada cromossomo, deve-se medir o tamanho dos braços do cromossomo com um paquímetro. Utiliza-se esse aparelho para se obterem várias medidas dos segmentos e, no final,somam-se todos os segmentos para a obtenção da medida final.

Com base no tamanho dos braços do cromossomo, é calculada a RB(razão entre braços). A RB é a divisão entre o tamanho do braço maior do cromossomo pelo braço menor, conforme mostra a equação a seguir:

$R B$

$=\frac{\text { comprimento braço maior }}{\text { comprimento braço menor }}$ 
Também é calculado o IC (índice centromérico), que é a razão entre o tamanho do braço menor pelo tamanho total do cromossomo, multiplicado por 100, como mostra a equação a seguir:

$$
I C=\frac{\text { comprimento braço menor }}{\text { tamanho do cromossomo }} * 100
$$

Tabela 1. Classificação dos cromossomos

\begin{tabular}{cc}
\hline Razão entre braços - RB & Classificação \\
\hline $1,00-1,70$ & metacêntrico $(\mathrm{m})$ \\
$1,71-3,00$ & submetacêntrico $(\mathrm{sm})$ \\
$3,01-7,00$ & subtelocêntrico (st) \\
$>7,00$ & acrocêntrico (a) \\
\hline
\end{tabular}

Depois da etapa de classificação, os cromossomos de uma mesma classe precisam ser ordenados de forma decrescente com relação ao seu tamanho e pareados de acordo com a similaridade das características. Ao final desse processo, obtém-se o cariótipo, como mostra Fig. 1.

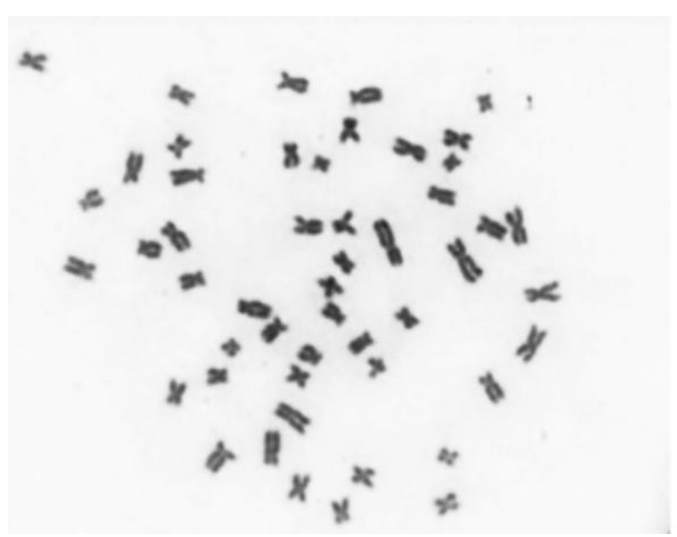

Figura 1. Cariótipo de peixe.

\section{MATERIAL E MÉTODOS}

Para obtenção de mitoses por tratamento in vivo, exemplares de três espécies foram capturados: Hopliasmalabaricus (13 indivíduos analisados, sendo seis machos e sete fêmeas), Hypostomusancistroides (seis indivíduos analisados, sendo quatro machos e duas fêmeas), Parauchenipterusgaleatus (dois indivíduos analisados, sendo um macho e uma fêmea). Os peixes capturados foram transportados vivos, em condições de oxigenação e temperatura adequadas, para o laboratório de Biodiversidade Molecular e Cromossômica de Peixes do Departamento de Genética e Evolução da Universidade Federal de São Carlos - UFSCar.
Assim, de acordo com o valor da RB, cada cromossomo é classificado nas quatro classes possíveis (metacêntrico, submetacêntrico, subtelocêntrico e acrocêntrico) (Levanet al., 1964), e o limite da RB é dado conforme mostra a Tab. 1.
Dependendo da espécie estudada e do escopo do estudo genético a ser realizado, outras classes de cromossomos podem ser consideradas (Levan et al., 1964; Abraham; Prasad, 1983; Andreata et al., 1993). m

sm

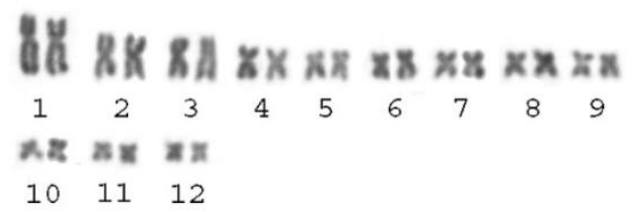

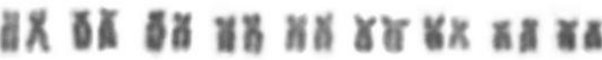
$\begin{array}{lllllllll}13 & 14 & 15 & 16 & 17 & 18 & 19 & 20 & 21\end{array}$ 조조 $\begin{array}{llll}22 & 23 & 24 & 25\end{array}$
No laboratório, foram mantidos em aquários climatizados, até serem processados para a obtenção dos cromossomos, seguindo as orientações do Comitê de Ética no Uso de Animais (Processo Ceua 07/2011) da Universidade Estadual de Ponta Grossa.

Os cromossomos foram obtidos segundo tratamento in vitro(Foresti et al., 1993).

As preparações cromossômicas obtidas foram capturadas, sob aumento de 100x, com utilização de óleo de imersão, por meio de um microscópio de epifluorescência (Olympus BX51) acoplado a uma câmera de captura (Olympus DP72). 
Neste trabalho,foi desenvolvido um sistema de geração automática e semiautomática de cariótipo de peixe. Esse sistema auxilia os especialistas da área na realização da montagem do cariótipo de peixe, mediante realização de parte das tarefas de maneira automática e semiautomática.

O softwareMatlab (The MathWorks, Inc., Massachusetts, EUA), disponível para Windows, Mac e Linux, foi utilizado para a implementação do sistema (Mauricio et al., 2017), viabilizando também uma interface gráfica para a realização das análises.

Para se iniciar a montagem do cariótipo de peixe, é necessário obter uma fotomicrografia (imagem) de células de peixe no estágio de metáfase. As imagens capturadas têm resolução de 1392x1040 pixels e foram gravadas usando-se o formato JPG (Joint Photographic Experts Group).

Posteriormente, é necessário fazer a segmentação dessa imagem. Segmentar uma imagem significa particionar essa imagem em partes ou objetos que a compõem. Na maioria das aplicações, a segmentação é a fase mais importante e mais difícil no processamento digital de imagens(Mauricio, 2017).Essa fase é uma das mais complexas, pois as imagens podem apresentar baixo contraste, ruídos, artefatos, cromossomos muito próximos uns dos outros e, às vezes,cromossomos sobrepostos.

Mediante o resultado da segmentação, com base nas características das áreas segmentadas, os cromossomos são identificados, contados,extraídos e verticalizados sendo finalmente ordenados em função do seu tamanho. O sistema ainda disponibiliza uma interface para que o usuário possa realizar a classificação dos cromossomos.

Essa análise foi feita utilizando-se o sistema desenvolvido pelo grupo de pesquisa para esse fim,com base no algoritmo apresentado em Mauricio (2017). O algoritmo em questão possui características autoconfiguráveis para identificar hemácias de diferentes espécies.Conforme pode ser visto em Mauricio et al. (2017), tais características foram utilizadas com modificações adequadas às especificidades para identificação e contagem de cromossomos.
$\mathrm{O}$ processo de cariotipagem de peixe nesse sistema consiste nos seguintes passos: (1) o usuário seleciona e carrega no sistema a imagem a ser processada. (2) O sistema define um limiar inicial, que é calculado automaticamente para a segmentação e posterior contagem dos cromossomos segmentados. (3) O usuário, mediante análise visual da contagem automática dos cromossomos, decide pela necessidade de ajustar o limiar com o Slider(barra),que pode ser observado na região inferior das Fig.2 e 3. O objetivo do controle assistido do limiar é obter o máximo de cromossomos automaticamente identificados. Uma representação do uso desta etapa é apresentada na Fig. 2. (4) O usuário pode utilizar uma opção disponível de criar linhas divisórias para cromossomos que ficaram justapostos na imagem segmentada e que o usuário reconhece ser dois cromossomos e não um cromossomo único. A linha pode ser desenhada na imagem colorida ou na imagem binária (branco e preto), etapa que pode ser visualizada na Fig.3(a).

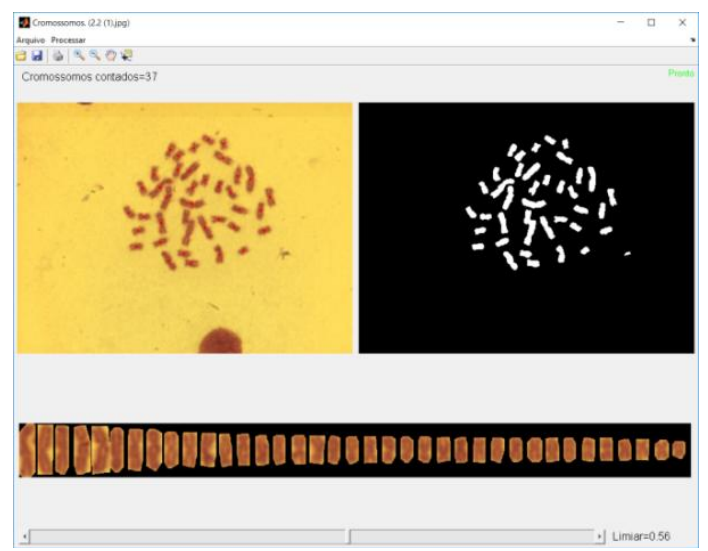

Figura 2. Segmentação e contagem assistida dos cromossomos.

Caso necessário, aplicar o zoom para facilitar o desenho da linha, como pode ser visualizado na Fig.3(b). (5) Uma quinta etapa consiste em realizar a limpeza de artefatos contados erroneamente, se necessário (opção "Limpar área" no menu "Processar"). Esta etapa pode ser visualizada na Fig.4. (6) Consiste na gravação dos resultados após verificação se todos os cromossomos foram identificados, contados e extraídos corretamente. O sistema grava as informações da contagem em uma planilha, conforme Tab. 2. 


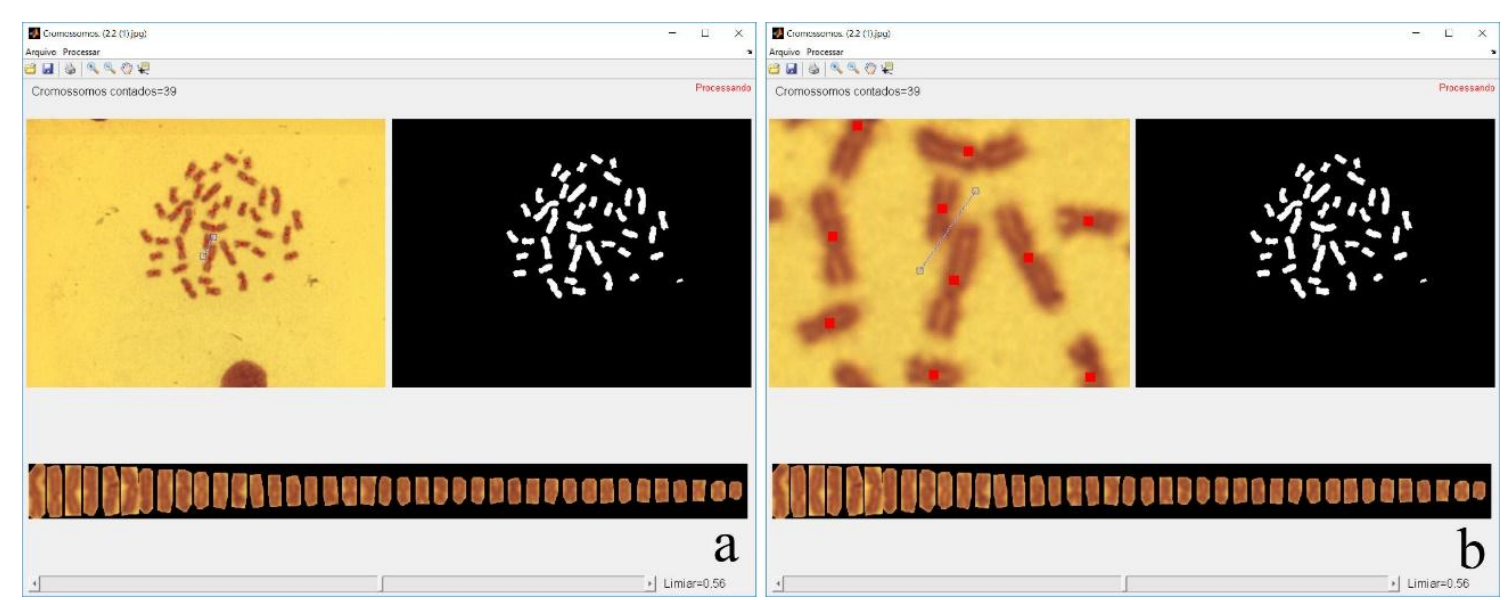

Figura 3. Separação dos cromossomos muito próximos, (a) linha e (b) linha com aplicação de zoom.

Para avaliar o desempenho do sistema de geração automática e semiautomática de cariótipo de peixe, foram selecionadas 100 imagens, obtidas de células de peixes no estágio de metáfase. O conjunto de imagens avaliadas inclui diferentes espécies de peixes. As espécies analisadas foram Hopliasmalabaricus (traíra);
Hypostomusancistroides (cascudo) e Parauchenipterusgaleatus (bagre-sapo). Essas imagens foram analisadas de duas maneiras: a primeira, de modo automático, feita pela ferramenta computacional, e a segunda, de modo semiautomático, feita pelo usuário.

Tabela 2. Informações gravadas sobre as contagens de cromossomos

\begin{tabular}{|c|c|}
\hline Informação & Descrição \\
\hline Imagem & Nome correspondente da imagem processada. \\
\hline Limiar T & Valor do limiar escolhido pelo usuário para a segmentação da imagem. \\
\hline $\begin{array}{l}\text { Número de linhas desenhadas } \\
\text { para separação }\end{array}$ & Número de linhas desenhadas para separação de cromossomos próximos. \\
\hline Limpeza de área & Número de limpezas de artefatos contados erroneamente. \\
\hline Contagem assistida & $\begin{array}{l}\text { Resultado final da contagem de cromossomos feita pelo usuário com o } \\
\text { auxílio do sistema. }\end{array}$ \\
\hline Contagem automática & Resultado final da contagem automática de cromossomos. \\
\hline
\end{tabular}

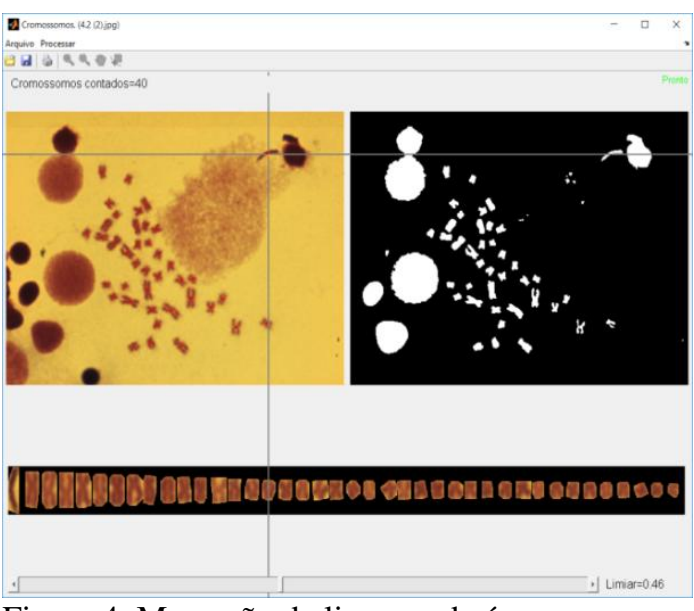

Figura 4. Marcação da limpeza de área.
As características visuais das imagens (e.g., forma, tamanho e quantidade dos cromossomos) são muito diferentes entre si. Por exemplo, o número de cromossomos varia entre 34 e 54 . Além das diferenças entre as espécies de peixe, existem as diferenças de cor de fundo, devido ao uso de filtros no microscópio, e a presença de artefatos, ou seja, estruturas que não são cromossomos e que dificultam a análise em questão. Esses artefatos podem ser, principalmente,o núcleo interfásico e restos celulares.

A análise feita automaticamente pelo algoritmo compreende as etapas de identificação, contagem, extração, verticalização e ordenação dos cromossomos analisados; a imagem gerada 
pelo sistema na análise automática pode ser visualizada na Fig.5.

A avaliação dessas etapas automáticas foi feita comparando-se com os resultados obtidos por usuários da ferramenta por meio do método semiautomático.

A ferramenta oferece ao usuário uma interface para auxiliar a classificação e o pareamento dos cromossomos, mas não realiza essas etapas por métodos automáticos.

$\mathrm{Na}$ análise semiautomática, as imagens selecionadas foram analisadas por quatro pessoas diferentes, sendo dois usuários sem experiência na área (usuário 1 e usuário 2) e dois usuários experientes na área (usuário 3 e usuário 4).

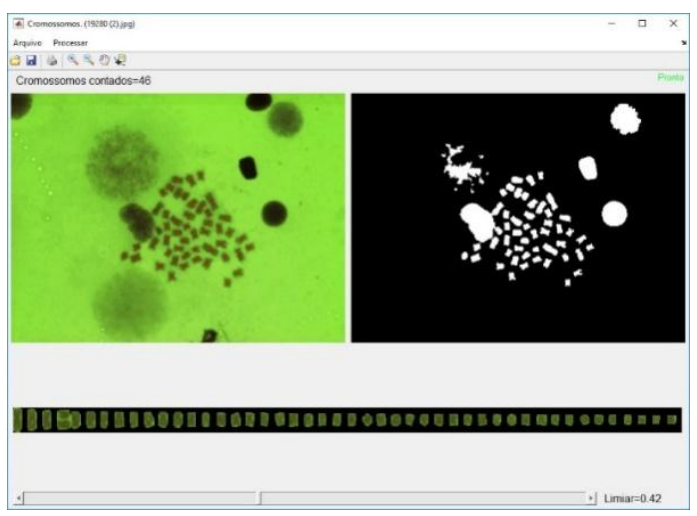

Figura 5. Análise automática.

A imagem gerada pelo sistema na análise semiautomática pode ser visualizada na Fig.6.

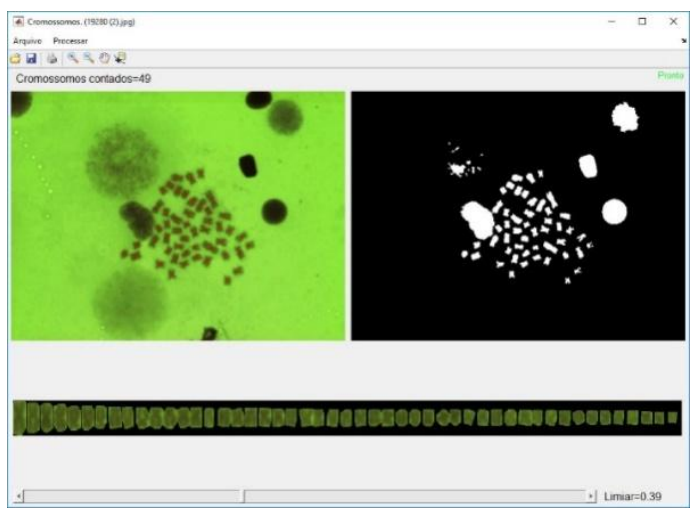

Figura 6. Análise semiautomática.

A avaliação do sistema foi feita utilizando-se como referência a média das contagens feitas pelos quatro usuários.

\section{RESULTADOS E DISCUSSÕES}

Considerando-se as 100 imagens processadas pela ferramenta desenvolvida e a média da contagem dos quatro usuários, foram contados, no total, 4348 cromossomos.

O método automático apresentou a contagem de 4190 cromossomos, o que representa uma identificação automática de aproximadamente $96,4 \%$ do total de cromossomos presentes nas imagens. A distribuição das contagens dos dois métodos é apresentada na Fig.7.

No gráfico das diferenças, apresentado na Fig.8, é possível observar a variação entre as contagens produzidas pelas duas análises. Observa-se ainda que o número de cromossomos presentes nas amostras está na faixa de 34 a 54, concentrandose especialmente próximos de 39 e 52 cromossomos.

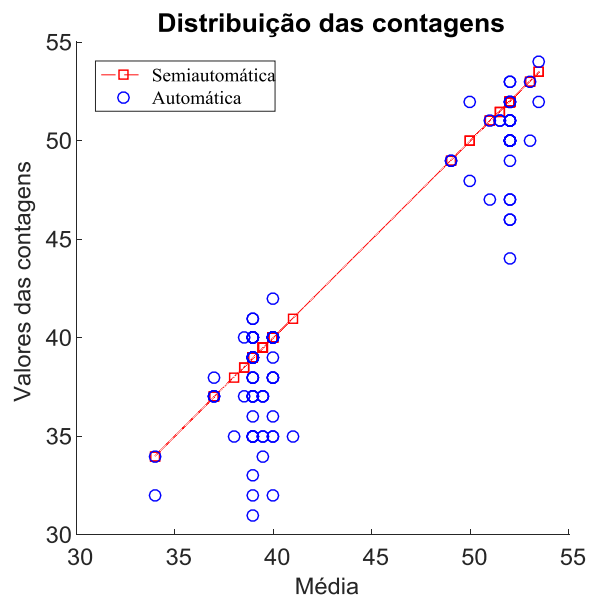

Figura 7. Contagem assistida por computador comparada com os resultados da contagem automática.

Os resultados indicam ainda que a análise automática produz, na maioria das amostras, contagens inferiores às contagens produzidas pela análise semiautomática, o que pode ser conferido nas Fig.7e 8.

Para avaliar a análise semiautomática da ferramenta desenvolvida, foram utilizadas 100 imagens, que foram analisadas por quatro usuários diferentes. A cada imagem analisada, foram gravadas informações, em conformidade com a Tab. 2, referentes ao seu processamento. 


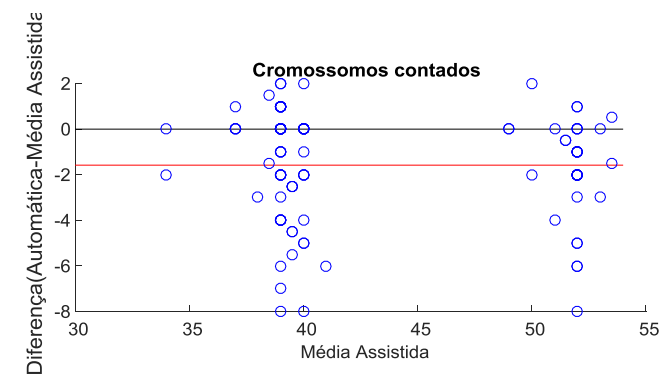

Figura 8. Gráfico de diferenças entre a contagem automática e a média da contagem assistida.
A Tab. 3 apresenta a correlação entre os quatro usuários que utilizaram a ferramenta para a contagem dos cromossomos. Esses resultados se referem à utilização do método semiautomático. Observando-se os valores sempre maiores do que 0,99, pode-se concluir que, com o auxílio da ferramenta, os usuários produziram contagens com forte correlação. Em razão da forte correlação entre as contagens, o valor adotado como referência para a comparação com o método automático foi a média dessas quatro contagens.

Tabela 3. Correlação das contagens realizadas pelos quatro usuários

\begin{tabular}{ccccc}
\hline & Usuário 1 & Usuário 2 & Usuário 3 & Usuário 4 \\
\hline Usuário 1 & 1,0000 & 0,9974 & 0,9967 & 0,9972 \\
Usuário 2 & 0,9974 & 1,0000 & 0,9967 & 0,9964 \\
Usuário 3 & 0,9967 & 0,9967 & 1,0000 & 0,9974 \\
Usuário 4 & 0,9972 & 0,9964 & 0,9974 & 1,0000 \\
\hline
\end{tabular}

A distribuição dessas contagens e a respectiva média podem ser observadas na Fig.9.

Apesar de 96,4\% ser um bom resultado de identificação automática dos cromossomos, é importante lembrar que, em alguns casos, essa contagem inclui falsos positivos. Em média, ocorreram falsos positivos em 26 imagens para cada usuário, conforme pode ser visto na Tab. 4. Isso ocorre quando um artefato possui características semelhantes aos cromossomos, o que leva o algoritmo a contá-los equivocadamente como cromossomos.

Exemplos de falsos positivos podem ser vistos na Fig. 10; à direita da imagem, é possível notar seis estruturas identificadas erroneamente como cromossomos.

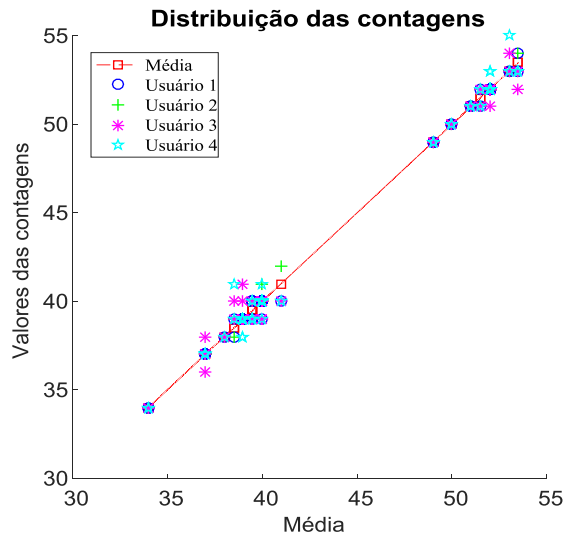

Figura 9. Distribuição das contagens realizadas pelos quatro usuários.
Tabela 4. Número de imagens com uso da opção "Linha" e da opção "Limpar área"

\begin{tabular}{ccc} 
& Opção "Linha” & $\begin{array}{c}\text { Opção "Limpar } \\
\text { área” }\end{array}$ \\
\hline Usuário 1 & 68 & 20 \\
Usuário 2 & 62 & 31 \\
Usuário 3 & 77 & 28 \\
Usuário 4 & 78 & 27 \\
Média & 71,25 & 26,50 \\
\hline
\end{tabular}

Com o auxílio da ferramenta, usando a opção "Limpar área", esses falsos positivos foram eliminados das contagens assistidas pelos usuários, mas estão presentes nos valores das contagens automáticas.

É possível identificar os falsos positivos incluídos na contagem automática mediante $o$ número de vezes que a opção "Limpar área" foi utilizada. A Tab. 5 apresenta o resultado da contagem automática excluindo 55 falsos positivos, o que representa $1,3 \%$ do total de cromossomos presentes nas amostras. Neste caso, o valor da identificação automática é de $95,1 \%$ dos cromossomos, o que ainda é um resultado de grande utilidade, pois significa que $95,1 \%$ dos cromossomos são identificados corretamente e de forma automática, confirmado pela correlação muito forte, $r=0.93$, entre os dois métodos. 


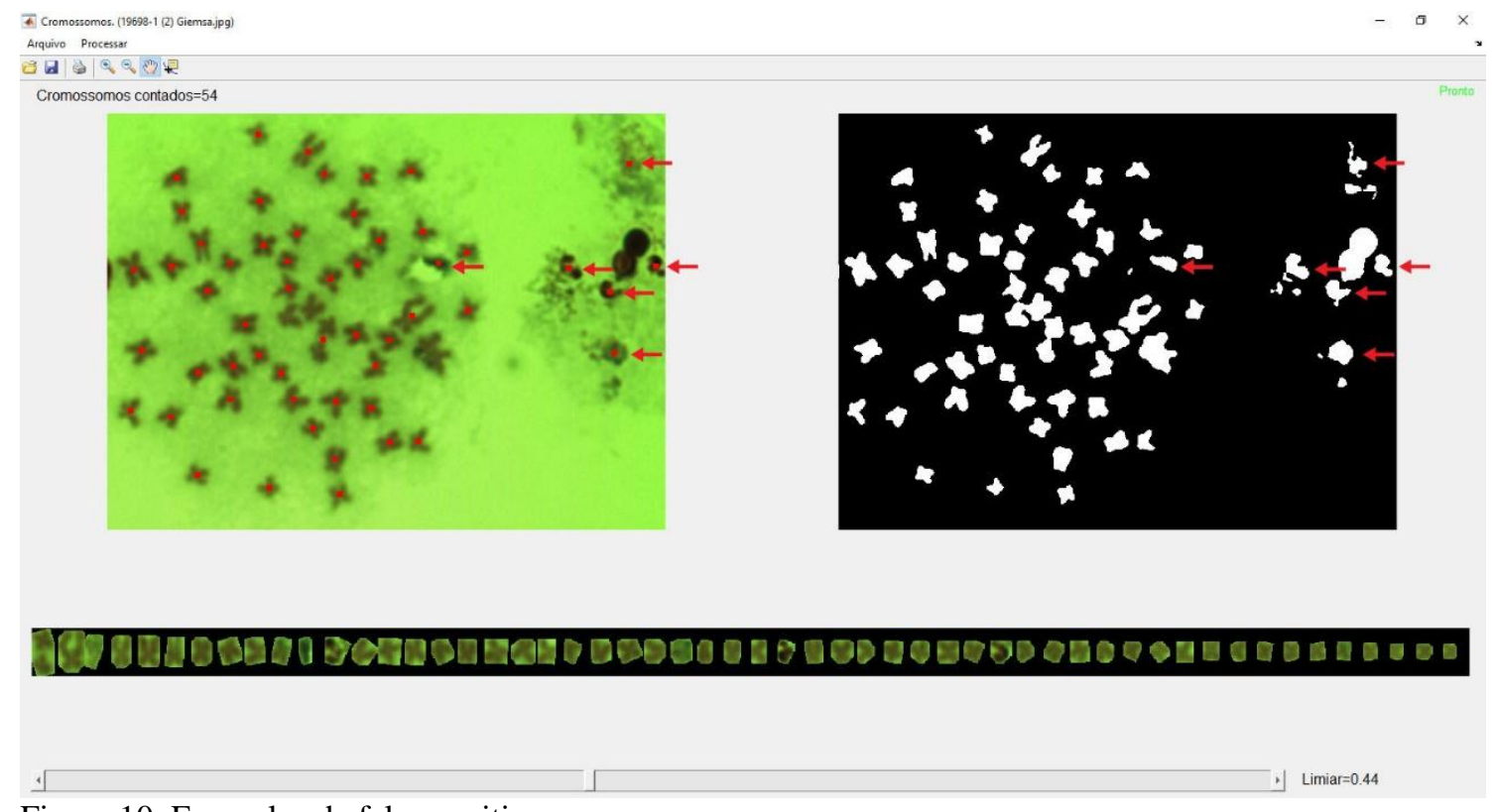

Figura 10. Exemplos de falso positivo.

Tabela 5. Total de cromossomos contados, excluindo falsos positivos

\begin{tabular}{cc}
\hline Automática & Semiautomática \\
\hline 4135 & 4348 \\
\hline
\end{tabular}

Após a eliminação dos falsos positivos, a divergência existente entre a contagem automática e a semiautomática se deve às ocorrências de falsos negativos. Nos casos de cromossomos justapostos ou próximos a artefatos, resultando em uma região com tamanho aumentado na imagem binária,ocorre falha na identificação deles.Na Tab. 5, é possível observar que o método automático produziu uma contagem com 213 cromossomos a menos que o método semiautomático devido aos falsos negativos. Isso representa 4,9\% do total de 4348 cromossomos. Exemplos de falsos negativos podem ser vistos na Fig.11.
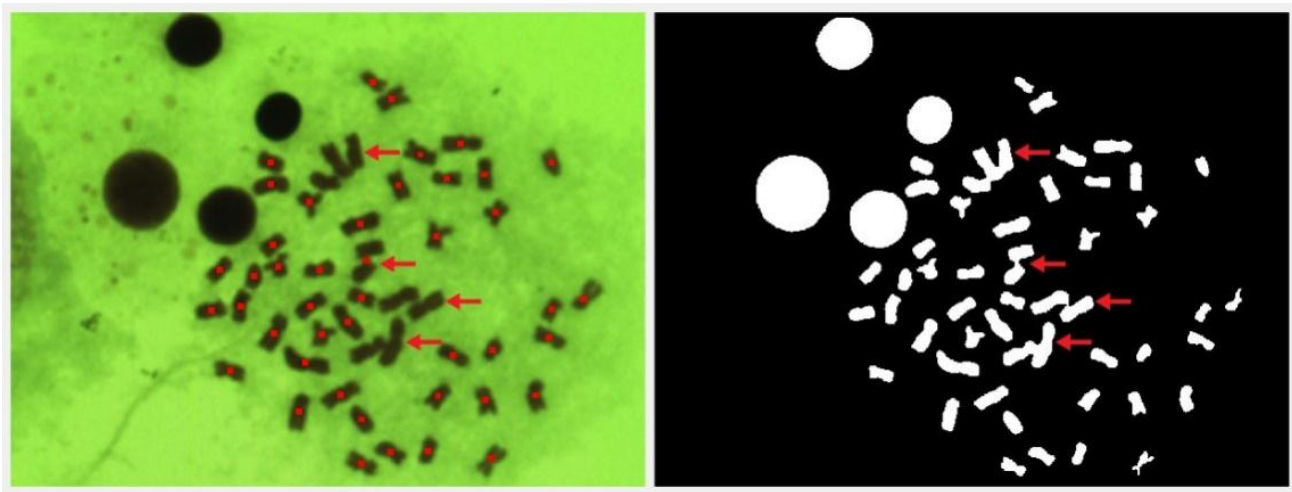

Figura 11. Exemplos de falsos negativos.

\section{CONCLUSÕES}

Os estudos de citogenética evolutiva apresentam importantes contribuições para a compreensão da evolução das espécies animais e das interferências provocadas pelo ambiente no qual estão inseridas, auxiliando na construção de uma visão mais ampla dos ecossistemas em que se encontram essas espécies. Entre as atividades desses estudos, a geração do cariótipo é das mais complexas e trabalhosas e, por isso, a ferramenta proposta contribui efetivamente para otimizar 
essas atividades ao melhorar a eficiência para a geração do cariótipo e a confiança nos resultados e, desse modo, possibilitar ao profissional maior produtividade.Os resultados indicam que a ferramenta provê um auxílio efetivo na realização das atividades para geração do cariótipo de peixes, ao identificar corretamente, em média, 95,1\% dos cromossomos. Em imagens com bom contraste e foco,obtém-se identificação correta de $100 \%$ dos cromossomos. Com isso, pode-se estimar a vantagem em tempo que tal ferramenta traria aos usuários, corrigindo $1,3 \%$ de cromossomos contatos equivocadamente e $4,9 \%$ dos cromossomos que não tinham sido contados. A ferramenta também auxilia ao extrair os cromossomos das imagens e ordená-los por tamanho após ajustar sua orientação na vertical.Além disso, fornece uma interface interativa para que o usuário possa classificar os cromossomos e pareá-los,o que facilita a manipulação deles para a montagem do cariótipo.

\section{AGRADECIMENTOS}

Os autores agradecem ao professor Marcelo RicardiVicari, por viabilizar o processo de aquisição das amostras de peixes, junto ao Comitê de Ética local, e à Josiane Baccarin Traldi, pelo apoio nas atividades de contagem neste trabalho.

\section{REFERÊNCIAS}

ABRAHAM Z.; PRASAD, P.N. A system of chromosome classification and nomenclature. Cytologia, v.48, p.95-101, 1983.

ANDREATA A.A. et al. Chromosome studies in Hypoptopomatinae (Pisces, Siluriformes, Loricariidae). Cytogenet. Cell. Genet., v.63, p.215-220, 1993.
ARTONI R.F.; VICARI, R.M.; BERTOLLO, L.A.C. Citogenética de peixes neotropicais: métodos, resultados e perspectivas. Biol. Health Sci., v.6, p.43-60, 2000.

BRESSANE-NETO, A.F.et al. Desenvolvimento de um software para cariotipagem de cromossomos de peixes. In: CONGRESSO BRASILEIRO DE GENÉTICA, 51., 2005, Aguas de Lindoia. Anais...Aguas de Lindoia, SP: Sociedade Brasileira de Genética, 2005. (Resumos).

FARIA, E.R. Sistema para a montagem de cariótipo de peixe baseado em conjuntos difusos. Uberlândia: Universidade Federal de Uberlândia, 2006.

FORESTI, F.; OLIVEIRA, C.; TOLEDO, F.A.L.A method for chromosome preparations from large fish specimens using in vitro shortterm treatment with colchicine. Experientia, v.49, p.810-813, 1993.

GUERRA, M.L. Introdução à citogenética geral. Rio de Janeiro: Guanabara Koogan, 1988.

LEVAN, A.; FREDGA, K.; SANDBERG, A.A. Nomenclature for centromeric position on chromosomes. Hereditas, v.52, p.201-220, 1964.

MAURICIO C.R.M. Contador de células vermelhas baseado em imagens para múltiplas espécies de animais silvestres e domésticos. 2017. 92f. Tese (Doutorado em Engenharia Elétrica e Informática Industrial) - Universidade Tecnológica Federal do Paraná, Curitiba, PR.

MAURICIO C.R.M. et al. Image-based red blood cell counter for multiple species of wild and domestic animals. Arq. Bras. Med. Vet. Zootec., v.69, p.75-84, 2017.

O'CONNOR, C. Karyotyping for chromosomal abnormalities. Nature Educ., v.1, p.27, 2008. 